\title{
Study on the Retention and Distributions of the Copper-Based Preservative in Standing Tree Chinese Fir (Cunninghamia lanceolata)
}

\author{
Youhua Fan, ${ }^{1}$ Yong Wang, ${ }^{1}$ Ninghua Yu, ${ }^{2}$ Layun Deng, ${ }^{1}$ and Zejun Chen ${ }^{1}$ \\ ${ }^{1}$ Hunan Forestry Academy, Changsha 410004, China \\ ${ }^{2}$ Quality Supervision Test Center for Forest Products of Hunan, Changsha 410004, China \\ Correspondence should be addressed to Youhua Fan; yh_fan@163.com
}

Received 22 April 2016; Revised 20 June 2016; Accepted 3 July 2016

Academic Editor: Kaveh Edalati

Copyright ( 2016 Youhua Fan et al. This is an open access article distributed under the Creative Commons Attribution License, which permits unrestricted use, distribution, and reproduction in any medium, provided the original work is properly cited.

In spite of some studies about the wood permeability and its improving measures, some progress has been made to study the diffusion and transmission of preservative solutions in standing trees. In the present study, copper- (Cu-) based preservative with other reagents is injected into the standing tree Chinese fir using sap-flow method. The chemical compositions of the retreated woods are analyzed with Fourier transform infrared spectroscopy (FTIR) and X-ray photoelectron spectroscopy (XPS). The samples from different height positions are analyzed with scanning electron microscope (SEM) and atomic absorption spectroscopy (AAS) to obtain microstructures and preservative retention, respectively. The results indicate that the preservative solutions with lower concentrations are more conducive to diffusion and transmission in the wood. Moreover, the preservative retention at different height position has a greater concentration gradient for composite preservative solutions than those of the single preservative solutions. Solidified preservative particles are observed in xylem rays with SEM. The results of the present study provide some useful information for the functional design of the target wood products.

\section{Introduction}

Wood is a complex biomass material constituted mainly of cellulose, hemicelluloses, lignin, and an amount of extractives. It is widely used in building, furniture, paper pulp production, and so forth, for its advantages of high strengthweight ratio, impact resistance, and high process ability and especially for its sustainable and environmentally friendly natural properties [1]. Nevertheless, wood is a type of biological composite material, which is susceptible to outdoor environment. Defects such as decay and worm holes are some of the problems playing a significant role in efficient utilization of wood. Numerous attempts have been made to prolong its service life in previous studies [2-7]. Antiseptic treatment of wood is an effective method to prolong its service life using chromated copper arsenate (CCA) and alkaline copper quaternary (ACQ) [8-11]. However, impregnation modification needs fixed equipment investment, complex processes, high energy consumption, and environmental pollutions [12-14].
Chinese fir is one of the most important commercial timber species in China, which accounts for more than $90 \%$ of the amount of deforestation. However, defects such as low hardness, low density, and easy decay are unfavorable factors to limit their application outdoors as structural materials. Therefore, antiseptic treatment is essential to prolong the service life and expand the applications scope of the fast-growing woods.

Stumpage treatment dates back to the study of Iida et al. in 1990s [15], who firstly dyed the standing tree by using sap-flow method for effective utilization of lesser-used species. Those dyeing woods have been shown to grow comparatively large discoloration in the color. Subsequently, Zhao dyed fifty-eight species of hardwood and three species of softwood using the similar injection method [16]. Despite the deficiency of uneven dyeing, energy consumption is not needed in this method for the flow of the liquid in the tree by transpiration.

The staining material can be transported from the bottom of the trunk to the top trunk of the standing tree by 
transpiration; inspired by the above ideas, copper- $(\mathrm{Cu}-)$ based preservatives with other reagents are injected into the Chinese fir using the sap-flow method. The aim of our experiment is (i) to investigate the variation of preservative retention with the tree height and (ii) assess the effect of additive on the transmission and diffusion of the preservatives in the living trees.

\section{Materials and Methods}

2.1. Materials. Copper carbonate basic $\mathrm{Cu}_{2}(\mathrm{OH})_{2} \cdot \mathrm{CO}_{3}$, polyethylene glycol with molecular weight of 400 , and ammonia water were obtained from Sinopharm Chemical Reagent Co., China. Double-distilled water was used in the experiments.

2.2. Data Collections. The entire data collection process was carried out according to the method of GB/T 23229-2009 [17]. The mature Chinese fir trees, 20 years old, used for experiments were located at 28.12 degrees north and 113.06 degrees east. The experimental trees located more than 20 meters away from the watershed. The tree diameters at breast height (the height from the ground $1.4 \mathrm{~m}$ ) were $20 \mathrm{~cm}$ to $24 \mathrm{~cm}$ with average of 2250 trees per hectare. The average temperature was $33.6^{\circ} \mathrm{C}$ during the experimental period from June to September.

The copper carbonate basic was dissolved into ammonia water solution. The concentrations of the copper carbonate basic solutions were $2 \mathrm{wt} . \%, 4 \mathrm{wt} . \%$, and $6 \mathrm{wt} . \%$, respectively. The solutions were divided into two groups: one group was single preservative solution $(\mathrm{Cu}-\mathrm{NH})$ and the other was composite preservative solution via adding the additive, namely, polyethylene glycol, with its content of $5 \mathrm{wt} . \%$ (Cu-NH-PEG).

The stumpage treatment procedures were carried out as follows. Firstly, two holes with diameter of $10 \mathrm{~mm}$ were drilled using a drill bit on the symmetric position of the trunk. The holes are $30 \mathrm{~cm}$ high above the ground. The holes were supposed to reach the tree pith. And then, the holes were connected with plastic bottles of preservative solutions using a $Y$ type plastic pipe. The plastic bottle was kept above $80-100 \mathrm{~cm}$ from the ground. The total injection volume of the preservative solutions was 30 liters within four weeks. The target trees were cut down after 4-8 weeks of the treatment to solidify the preservative solutions. Three parallel experiments were carried out with the same concentration of the preservative solutions. The treatment procedures were shown in Figure 1.

2.3. Sample Analysis and Characterization. In the experimental tree, sawdust was collected using sampling cone every two meters. Counting from the tree roots, the samples were identified as the first, second, third, and fourth part. At the same saw plane, four samples were collected for analysis of the preservative retention. The preservative retention (expressed as $\mathrm{CuO}$ ) was analyzed according to the method of GB/T 23229-2009 [17]. The sampling schematic diagram for detecting preservative retention was shown in Figure 2.

Sawdust was smashed by high speed mill, 100-mesh beads were used for X-ray diffraction (XRD) analysis by Rigaku D/max-2000PC, XRD scans operating with a $\mathrm{Cu}$ anode at $40 \mathrm{kV}$ and $50 \mathrm{~mA}$ in the range of $2 \theta$ value between $10^{\circ}$ and $70^{\circ}$

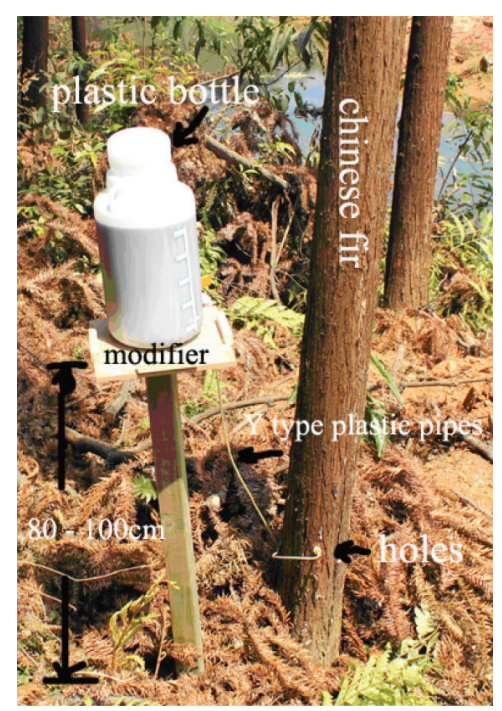

FIGURE 1: Illustration of the stumpage modification procedures on Chinese fir.

with a speed of $8^{\circ} / \mathrm{min}$. The chemical compositions of the resulting samples were investigated by Nicolet 6700 Fourier transform infrared spectrometer (FTIR) spectroscopy (Thermo Scientific). The surface compositions of the samples were determined by X-ray photoelectron spectroscopy (XPS). The XPS measurements were performed using an EscaLab 250Xi XPS spectrometer (Thermo-VG Scientific) with an Al $\mathrm{Ka} \mathrm{X}$-ray source $(15 \mathrm{kV}, 10 \mathrm{~mA})$ and an analytical chamber with a base pressure of $10^{-6} \mathrm{~Pa}$. All binding energies (Bes) were referred to the $\mathrm{C} 1 \mathrm{~s}$ peak $(284.6 \mathrm{eV})$ arising from surface hydrocarbons (or adventitious hydrocarbon). The samples used for SEM analysis were prepared by slip-propelled slicer from the experimental tree trunk every two meters. The morphologies were examined by TM 3000 scanning electron microscope (HITACHI), using an accelerating voltage of $15 \mathrm{kV}$.

\section{Results and Discussion}

3.1. XRD Analysis. XRD analysis is used to investigate the phase evolution of the preservative treated samples. The XRD pattern of the pure Chinese fir powder is shown in Figure 3(a). The diffraction peaks observed at $16.1^{\circ}$ and $22.5^{\circ}$ are the characteristic diffraction peaks of the I type of wood cellulose (101) and (002) crystal plane in the structure cell. For the treated samples, the same diffraction peaks also appear in the corresponding position, which show that the addition of the modified agent does not destroy the crystalline form of the cellulose.

3.2. FTIR Studies. The chemical compositions of the Chinese fir treated under different preservative solutions are studied by using Fourier transform infrared spectroscopy (FTIR). The obtained spectra are shown in Figure 4. Several characteristic absorption peaks are observed in the range of 2000$500 \mathrm{~cm}^{-1}$. The band at $1743 \mathrm{~cm}^{-1}$ is identified to the carboxyl 


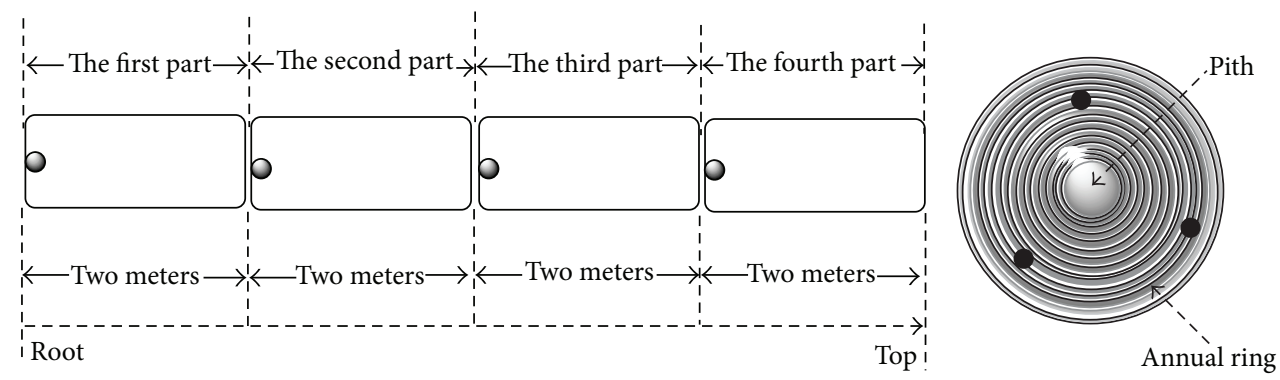

Sampling point

FIgURE 2: The sampling schematic diagram for detecting modifier retention.

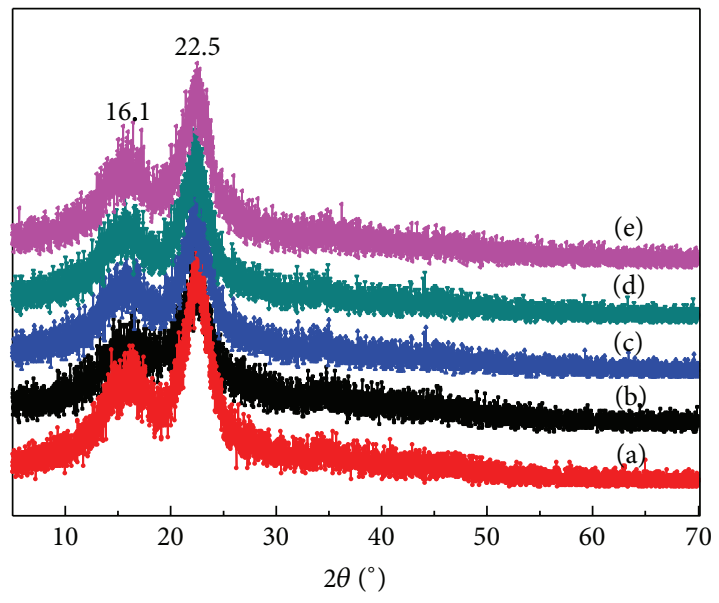

FIGURE 3: XRD patterns of (a) Chinese fir powder; (b) the first part; (c) the second part; (d) the third part; (e) the fourth part of the $2 \%$ $\mathrm{Cu}-\mathrm{NH}$ treated Chinese fir.

stretching vibration in carboxylic acid groups in hemicellulose (Figure $4(\mathrm{a})$ ). The band at $1510 \mathrm{~cm}^{-1}$ is assigned to aromatic skeletal vibration in lignin [18]. The bands at 1427 and $896 \mathrm{~cm}^{-1}$ are assigned to the absorption of the beta bonds stretching the cellulose. For the treated samples, the band density at $1743 \mathrm{~cm}^{-1}$ has a slight reduction. The reduction of the band is attributed to the reactions between copper and carboxylic groups that have taken place, while the cellulose acts as a stabilizer of the $\mathrm{Cu}-\mathrm{NH}$ complex in solution [19-23]. Based on an analysis of the references, the groups of $-\mathrm{COOH}$, $-\mathrm{OH},-\mathrm{CHO}$, and so forth are the reactive groups to fix the metal ions. It can be seen from Figures $4(\mathrm{e})-4(\mathrm{~g})$ that the densities of the wide band at $1100-980 \mathrm{~cm}^{-1}$ increase obviously due to the asymmetric stretching vibration absorption of the $-\mathrm{CH}_{2}-\mathrm{O}-\mathrm{CH}_{2}-$ of the PEG additive. Other characteristic peaks have not changed significantly. From these data, it is concluded that the preservatives solutions have not changed the chemical compositions of treated wood.

3.3. Distribution of the Preservative Solutions. During the stumpage treatment procedures, the preservative solutions flow with the longitudinal tracheids along the truck from root

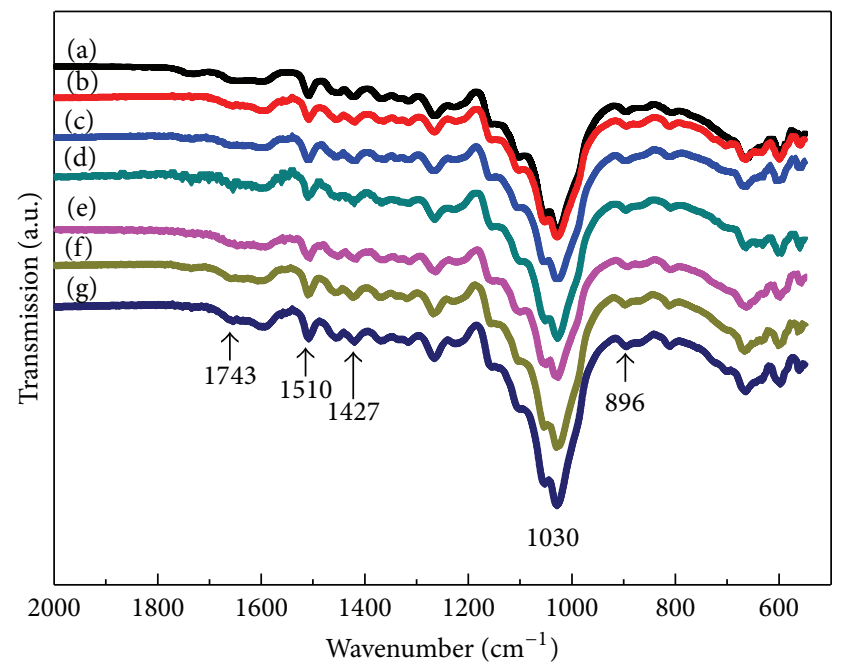

FIGURE 4: FTIR spectra of Chinese fir treated under different conditions. (a) Chinese fir; (b) $2 \mathrm{wt} . \% \mathrm{Cu}-\mathrm{NH}$ treated Chinese fir; (c) 4 wt.\% Cu-NH treated Chinese fir; (d) 6 wt.\% Cu-NH treated Chinese fir; (e) 2 wt.\% Cu-NH-PEG treated Chinese fir; (f) 4 wt.\% Cu-NHPEG treated Chinese fir; (g) 6 wt.\% Cu-NH-PEG treated Chinese fir.

to top of the canopy by the driving force of transpiration. The complicated capillary structure of wood has an uncertain influence on the permeability of the preservative solutions [24]. Therefore, it is necessary to analyze the vertical concentration distribution of the preservative in different height positions.

Figure 5 shows the copper-based compounds concentration, identified as copper oxidation, changing with the longitudinal height of the trunk. It can be seen that lower concentration of preservative is easier to diffuse into the wood. Moreover, the preservative retention reduces with the increase of longitudinal height of the trunk. However, high concentration of preservative forms large retention gradient due to the preservative enrichment and solidifying at the bottom of the trunk, which influences the homogenous distribution of the preservative in the trunk $[25,26]$. As seen from Figure 5(a), the preservative retention at the first part is $2.24 \mathrm{~kg} / \mathrm{m}^{3}, 4.24 \mathrm{~kg} / \mathrm{m}^{3}$, and $6.25 \mathrm{~kg} / \mathrm{m}^{3}$, respectively. At the fourth part of treated trees, the values are $0.97 \mathrm{~kg} / \mathrm{m}^{3}$, 


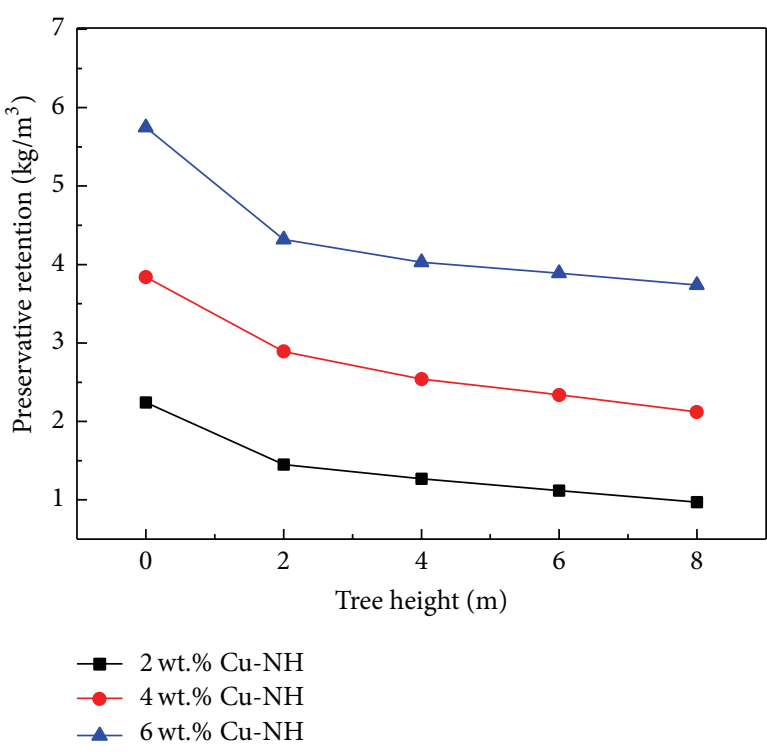

(a)

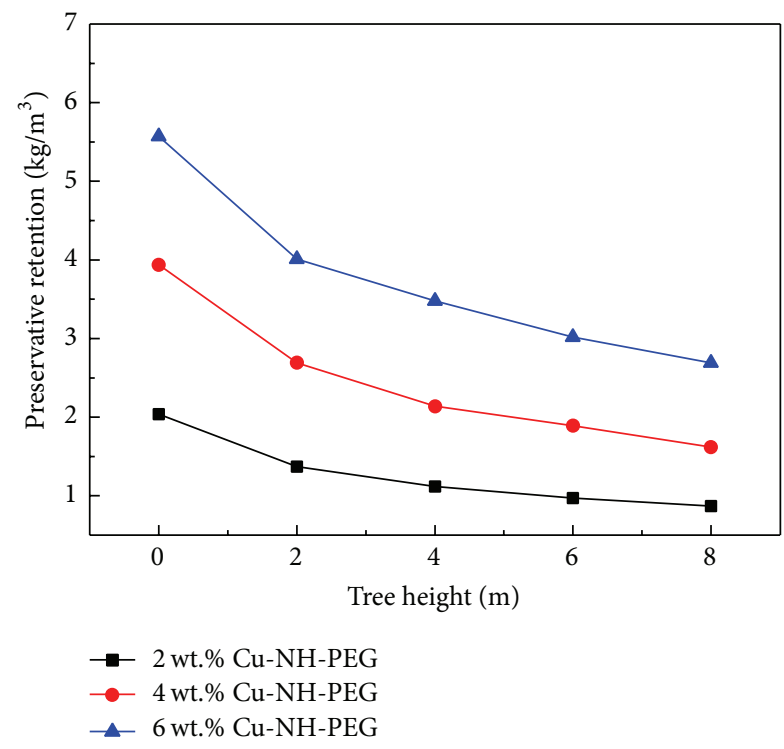

(b)

Figure 5: The preservative retention in different height positions in the treated Chinese fir by (a) the Cu-NH preservative solutions; (b) the $\mathrm{Cu}-\mathrm{NH}-\mathrm{PEG}$ preservative solutions.

$1.98 \mathrm{~kg} / \mathrm{m}^{3}$, and $3.14 \mathrm{~kg} / \mathrm{m}^{3}$, respectively. For the composite preservative solutions (Figure 5(b)), the preservative retention at the first part is $2.04 \mathrm{~kg} / \mathrm{m}^{3}, 3.94 \mathrm{~kg} / \mathrm{m}^{3}$, and $5.57 \mathrm{~kg} / \mathrm{m}^{3}$, respectively. At the fourth part, the values are $0.87 \mathrm{~kg} / \mathrm{m}^{3}$, $1.62 \mathrm{~kg} / \mathrm{m}^{3}$, and $2.69 \mathrm{~kg} / \mathrm{m}^{3}$, respectively. From these data, it is concluded that the preservative retention for the composite preservative solutions is lower than that of the single preservative solution.

Liquid movement from the roots to the atmosphere is controlled by the conductivity of the water pathway components [27]. Conductivities affecting liquid flow in the plant are hydraulic and diffusive [28]. In the course of the experiments, the effect of pressure on the fluid diffusion is constant. The effect of pressure is not considered. On a theoretical basis, modification of the tracheids size may potentially cause unfavorable effect on the transport of water in the xylem [27-29]. In other words, changing the shape of the tracheids or filling the tracheids space will also affect the diffusion of liquid in the xylem [30]. For the composite preservative solutions, higher relative molecular mass of PEG will fill the tracheids or pits or xylem rays, which will block the diffusion of the composite preservative solutions in the wood. Therefore, the retention of the preservatives in the woods is lower than that of the single preservative solutions [31, 32].

3.4. Morphology of the Samples. The morphologies of the samples are examined by SEM. The nontreated sample is tested as a reference. The porous structure of wood is clearly visible and nothing is filled in the tracheids and pits (Figure 6(a)). As shown in Figure 6(b) to Figure 8, the morphologies of the resulting samples are different from the nontreated sample. Longitudinal tracheids are the main diffusion channels of coniferous wood and their main functions are to transport water and support the tree. Water migration between the tracheids depends mainly on the pits of the tracheids walls. Tens or hundreds of pairs of pits connect the adjacent tracheids. Xylem rays are main diffusion channels of the axial direction for coniferous wood. Then, the main materials circulation systems consisting of the longitudinal tracheids, pits, and xylem rays are constructed for coniferous wood. During the transpiration, the preservative diffuses along the longitudinal direction from the root of the trunk pipe to the crown. Simultaneously, the preservatives diffuse in wood through the pits and the xylem ray. The preservatives are more inclined to solidify into particles during the diffusion along with the xylem rays. Therefore, the solid particles appear in the xylem rays, which are shown in Figure 6(b). In the root of the trunk, large numbers of solidified particles appear due to its local higher concentration. During the process of transmission from the root to the crown, the solidified preservative particles gradually reduce with the decrease of the concentration of preservative solution. To the fourth-part sample, the solidified particles appear in a few xylem rays. For 2 wt. $\%, 4$ wt. $\%$, and 6 wt.\%, three different concentrations of the preservative solutions, diffusion processions of the preservative solutions have similar variations, which are reflected in Figures 6, 7, and 8, respectively. Moreover, EDS spectrum of the solidified particles is given in Figure 6(f). The presence of $\mathrm{Cu}$ coming from the solidified particles is confirmed.

In comparison with the single preservative solution $\mathrm{Cu}-$ $\mathrm{NH}$, it is more difficult for the composite preservative solution $\mathrm{Cu}-\mathrm{NH}-\mathrm{PEG}$ to diffuse in the wood due to the increase of solution viscosity. Therefore, the preservative mainly solidifies in the root of the trunk. Concentration also has some influence on the diffusion of the preservative in wood. It can be seen from Figures 9-11 that low concentrations of preservative solutions are more conducive to diffusion and 

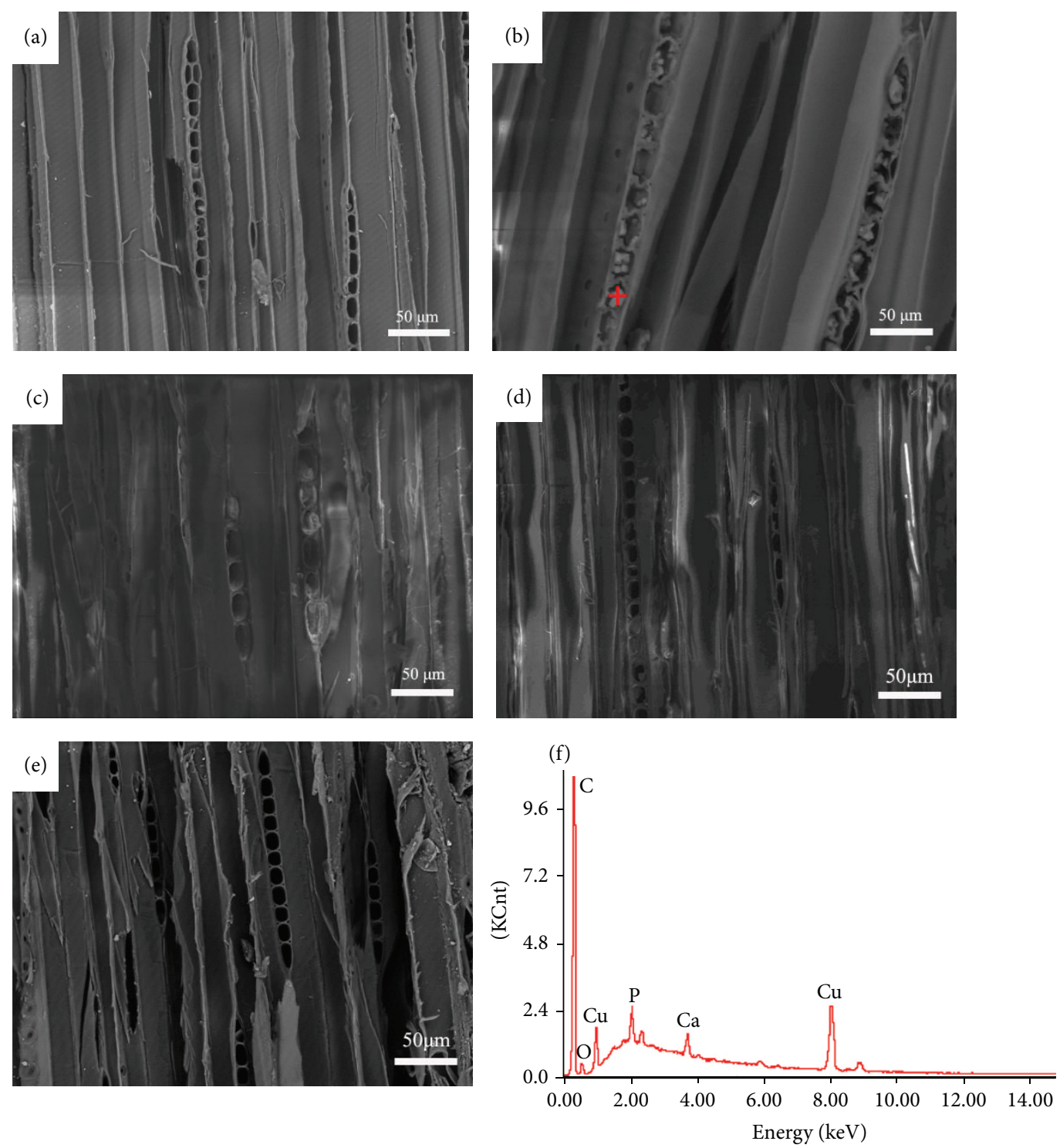

Figure 6: SEM of (a) the Chinese fir; (b) the first part; (c) the second part; (d) the third part; (e) the fourth part of $2 \% \mathrm{Cu}-\mathrm{NH}$ solution treated Chinese fir; (f) EDS spectrum of the solidified particle.

transport in wood, and then more solidifying particles appear in the xylem rays. Those results are consistent with the results shown in Figure 5. In the process of diffusion, the preservative can react with the active groups of the cellulose, such as hydroxyl, carbonyl, and aldehyde group, which will enhance the properties of wood. Physical filling solidified preservative in xylem rays can also effectively improve the mechanical properties of wood [33, 34].

3.5. XPS Measurements. The chemical compositions of the Chinese fir and the $2 \mathrm{wt} . \% \mathrm{Cu}-\mathrm{NH}$ solution treated Chinese fir are determined using XPS, which are shown in Figure 12. As seen from the treated Chinese fir specimen, the peak located at $934.17 \mathrm{eV}$ is attributed to the $\mathrm{Cu} 2 \mathrm{p}$ region of the copperbased preservative compared with the Chinese fir specimen $[35,36]$. The result shows that the copper-based preservative is solidified in the wood, which is consistent with the EDS result.

\section{Conclusions}

Copper- $(\mathrm{Cu}-)$ based preservative with other reagents is successfully injected into the standing tree Chinese fir by using sap-flow method. It is more difficult for the composite preservative solution to diffuse in the tree compared with the single preservative solution. For the single preservative solution, the preservative retention at the first part is $2.24 \mathrm{~kg} / \mathrm{m}^{3}$, $4.24 \mathrm{~kg} / \mathrm{m}^{3}$, and $6.25 \mathrm{~kg} / \mathrm{m}^{3}$, respectively. At the fourth part of treated trees, the values are $0.97 \mathrm{~kg} / \mathrm{m}^{3}, 1.98 \mathrm{~kg} / \mathrm{m}^{3}$, and $3.14 \mathrm{~kg} / \mathrm{m}^{3}$, respectively. For the composite preservative solutions, the preservative retention at the first part is $2.04 \mathrm{~kg} / \mathrm{m}^{3}$, $3.94 \mathrm{~kg} / \mathrm{m}^{3}$, and $5.57 \mathrm{~kg} / \mathrm{m}^{3}$, respectively. At the fourth part, 

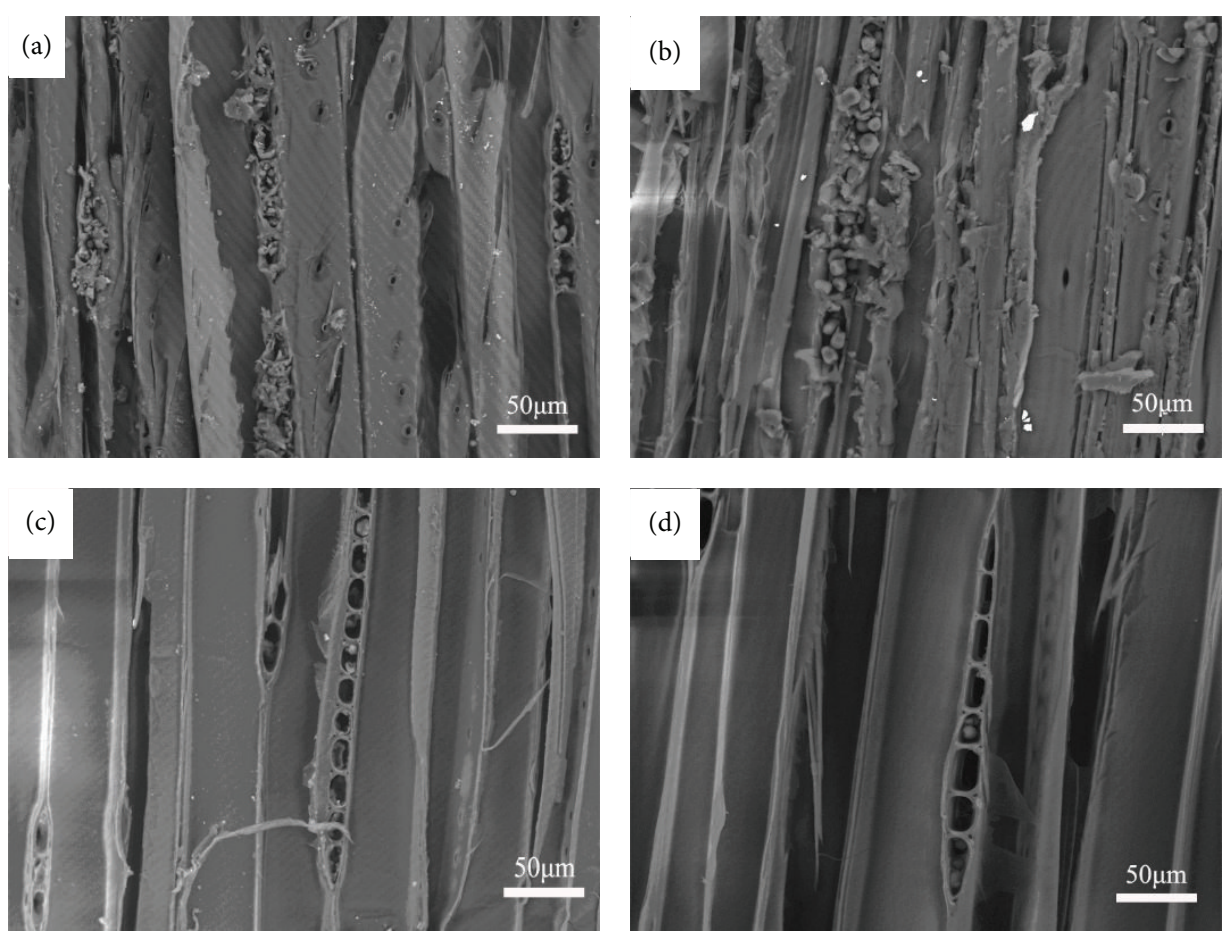

Figure 7: SEM of (a) the Chinese fir; (b) the first part; (c) the second part; (d) the third part; (d) the fourth part of 4 wt.\% Cu-NH solution treated Chinese fir.
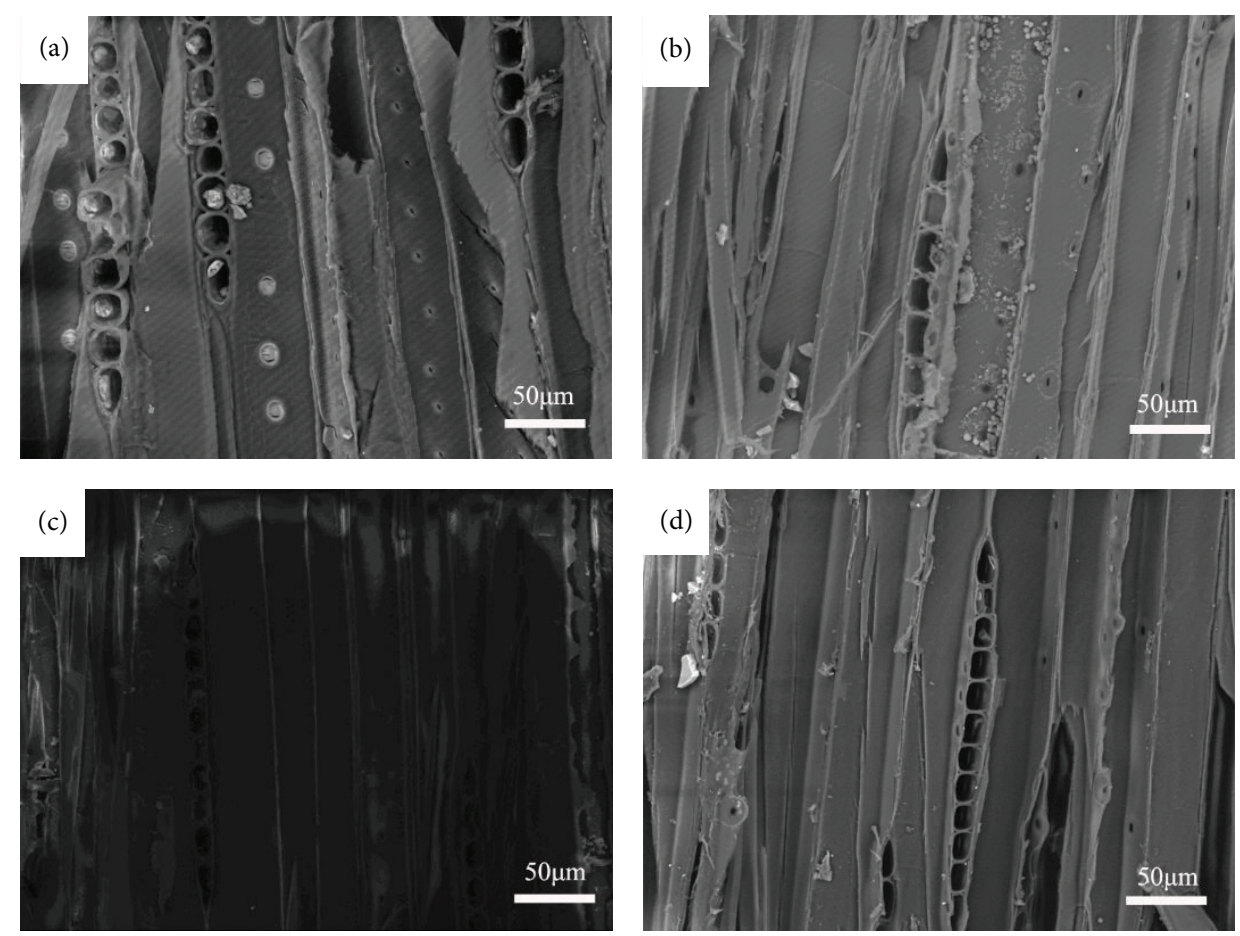

FIGURE 8: SEM of (a) the first part; (b) the second part; (c) the third part; (d) the fourth part of 6 wt.\% Cu-NH solution treated Chinese fir.

the values are $0.87 \mathrm{~kg} / \mathrm{m}^{3}, 1.62 \mathrm{~kg} / \mathrm{m}^{3}$, and $2.69 \mathrm{~kg} / \mathrm{m}^{3}$, respectively. The results are consistent with the SEM results. During the diffusion and transportation of the preservative solution, the preservatives are more easily solidified in the xylem rays.
In further research, the mechanical properties and dimensional stability combined with anticorrosion resistance of the resulting wood will be carried out to better understand the application value of this sap-flow method and provide 

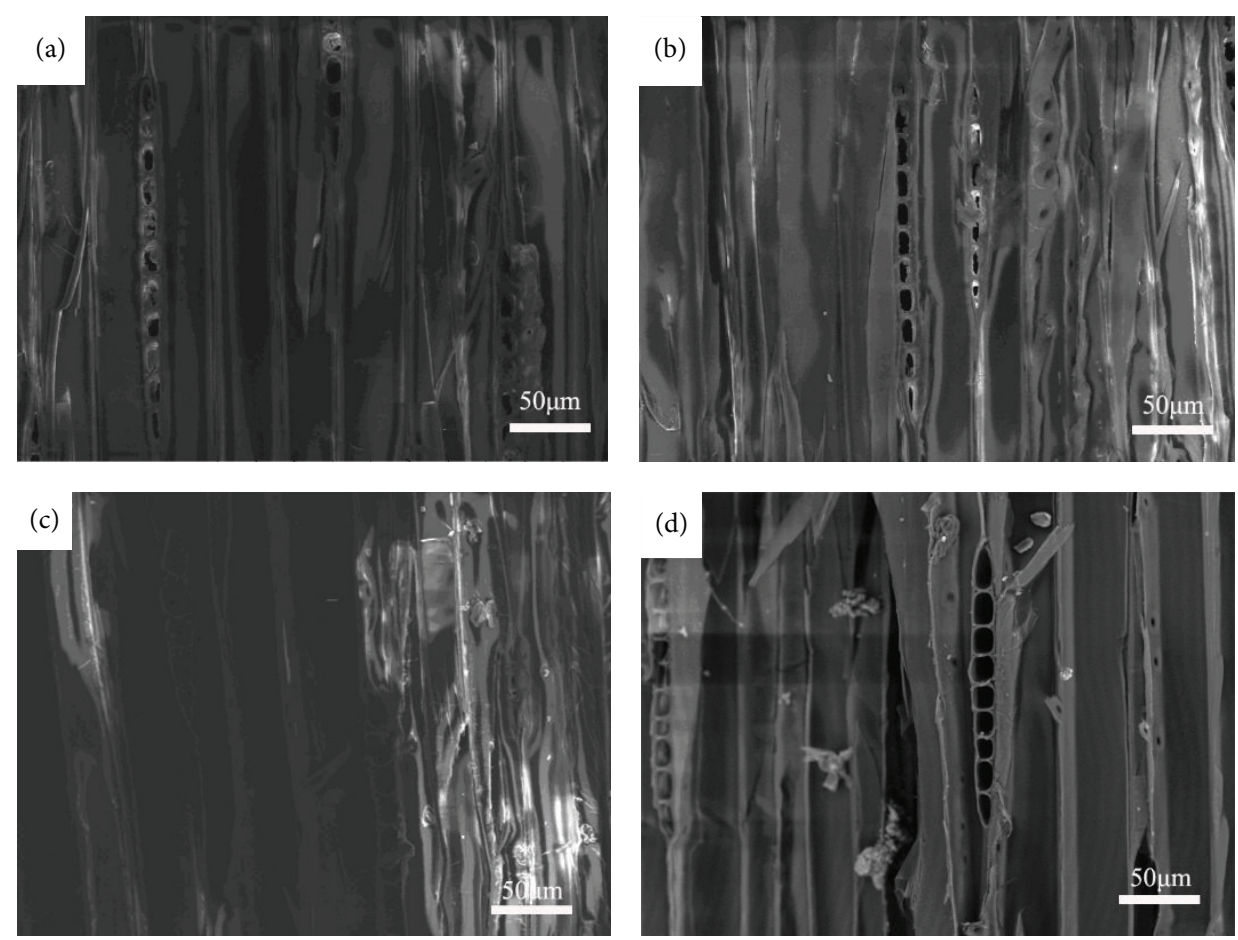

FIGURE 9: SEM of (a) the Chinese fir; (b) the second part; (c) the third part; (d) the fourth part of 2 wt.\% Cu-NH-PEG composite solution treated Chinese fir.
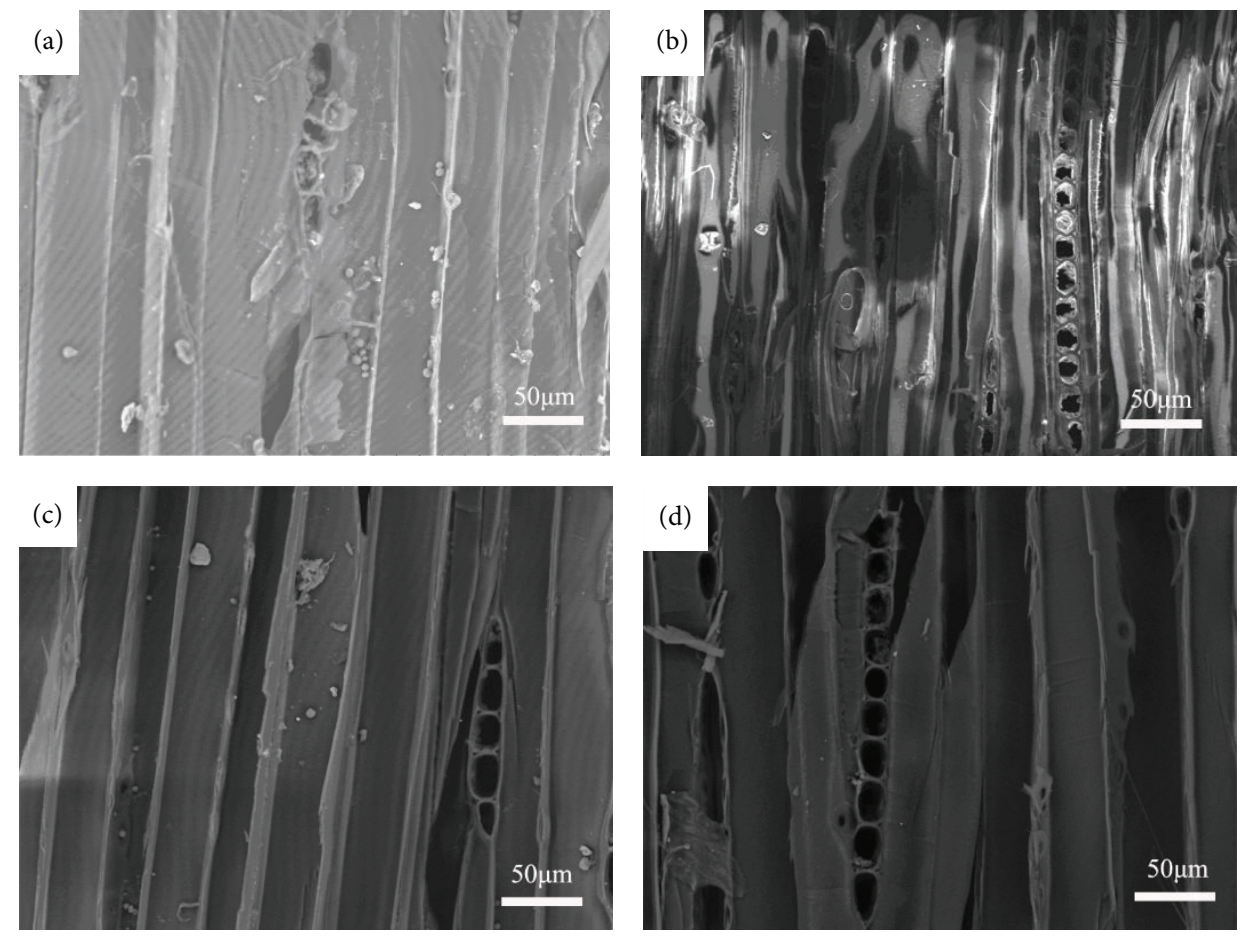

FIGURE 10: SEM of (a) the Chinese fir; (b) the second part; (c) the third part; (d) the fourth part of 4 wt.\% Cu-NH-PEG composite solution treated Chinese fir. 

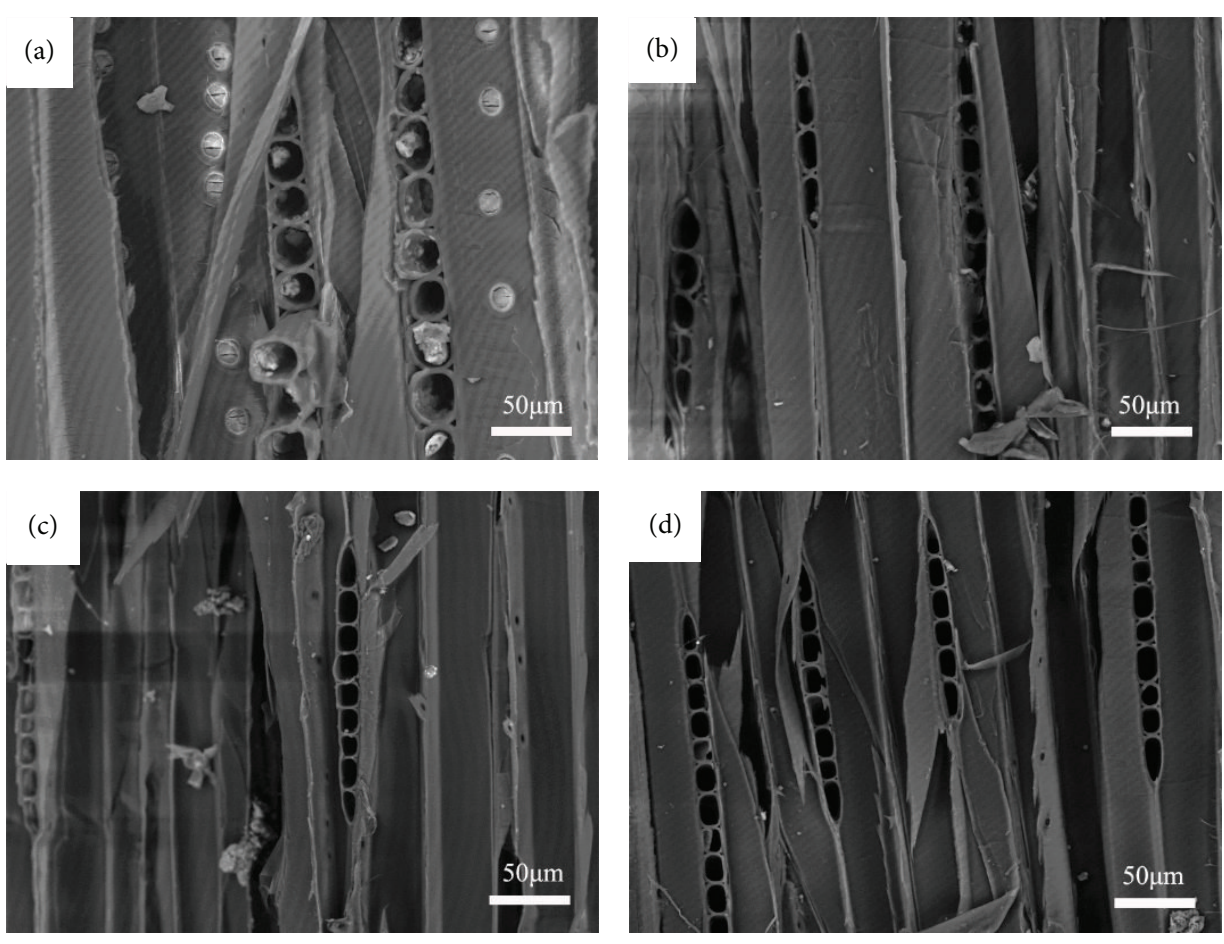

Figure 11: SEM of (a) the first part; (b) the second part; (c) the third part; (d) the fourth part of 6 wt.\% Cu-NH-PEG composite solution treated Chinese fir.

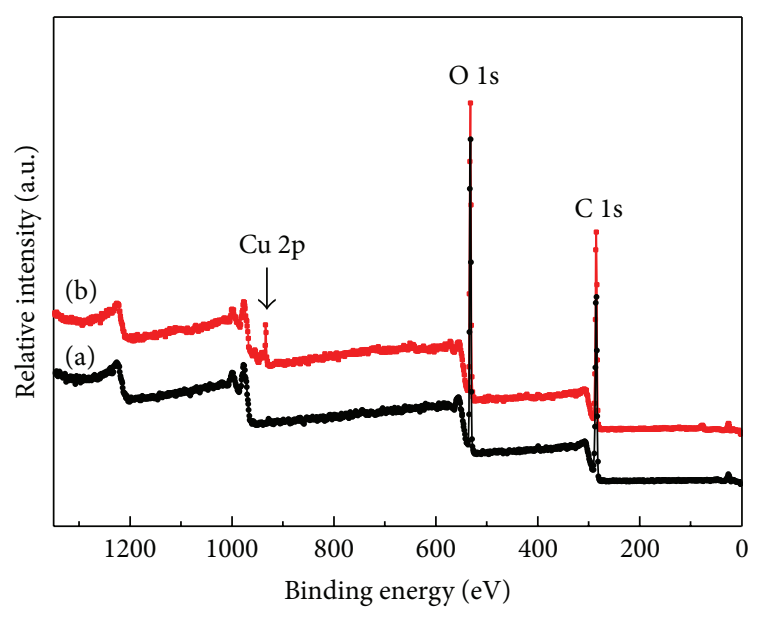

FIGURE 12: XPS spectra of (a) the Chinese fir; (b) the first part of 2 wt.\% Cu-NH solution treated Chinese fir.

technical support for the function design of the target wood products.

\section{Competing Interests}

The authors declare that they have no competing interests.

\section{Acknowledgments}

This work is supported by the Innovation Fund of Hunan Academy of Forestry (20130802) and the Science and
Technology Project of Science and Technology Department of Hunan Province (2012NK2002).

\section{References}

[1] C. M. Popescu and M. C. Popescu, "A near infrared specrtoscopic study of the structural modifications of lime (Tilia cordata Mill.) wood during hydrothermal treatment," Spectrochimica Acta Part A: Molecular and Biomolecular Spectroscopy, vol. 115, pp. 227-233, 2013.

[2] D. Aydemir, A. Kiziltas, E. E. Kiziltas, D. J. Gardner, and G. Gunduz, "Heat treated wood-nylon 6 composites," Composites Part B: Engineering, vol. 68, pp. 414-423, 2015.

[3] J.-Y. Kim, T.-S. Kim, I.-Y. Eom et al., "Characterization of pyrolytic products obtained from fast pyrolysis of chromated copper arsenate (CCA)- and alkaline copper quaternary compounds (ACQ)-treated wood biomasses," Journal of Hazardous Materials, vol. 227-228, pp. 445-452, 2012.

[4] E.-A. Salca and S. Hiziroglu, "Evaluation of hardness and surface quality of different wood species as function of heat treatment," Materials and Design, vol. 62, pp. 416-423, 2014.

[5] W. Tao, S. Shi, and C. N. Kroll, "Influences of wood preservation, lumber size, and weather on field leaching of red pine lumber," Journal of Hazardous Materials, vol. 260, pp. 296-304, 2013.

[6] N. Thaler and M. Humar, "Copper leaching from Copperethanolamine treated wood: comparison of field test studies and laboratory standard procedures," BioResources, vol. 9, no. 2, pp. 3038-3051, 2014.

[7] A. N. Papadopoulos and G. Pougioula, "Mechanical behaviour of pine wood chemically modified with a homologous series of linear chain carboxylic acid anhydrides," Bioresource Technology, vol. 101, no. 15, pp. 6147-6150, 2010. 
[8] L. L. Yu, J. Z. Cao, W. Gao, and H. T. Su, "Evaluation of ACQ$\mathrm{D}$ treated Chinese fir and mongolian scots pine with different post-treatments after 20 months of exposure," International Biodeterioration and Biodegradation, vol. 65, no. 4, pp. 585-590, 2011.

[9] D.-H. Lee, M. J. Lee, D.-W. Son, and B.-D. Park, "Adhesive performance of woods treated with alternative preservatives," Wood Science and Technology, vol. 40, no. 3, pp. 228-236, 2006.

[10] J. J. Slahor, C. C. Hassler, R. C. DeGroot, and B. D. Park, "Preservative treatment evaluation of red maple and yellow poplar with ACQ-B," Forest Product Journal, vol. 47, no. 4, pp. 50-54, 1997.

[11] Y. T. Ung and P. A. Cooper, "Copper stabilization in ACQD treated wood: retention, temperature and species effects," Holzals Rohund Werkstoff, vol. 63, no. 3, pp. 186-191, 2005.

[12] C. A. S. Hill, "Wood modification: an update," BioResources, vol. 6, no. 2, pp. 918-919, 2011.

[13] C. A. S. Hill, A. N. Papadopoulos, and D. Payne, "Chemical modification employed as a means of probing the cell-wall micropore of pine sapwood," Wood Science and Technology, vol. 37, no. 6, pp. 475-488, 2004.

[14] B. A. Lalonde, W. Ernst, G. Julien, P. Jackman, K. Doe, and R. Schaefer, "A comparative toxicity assessment of materials used in aquatic construction," Archives of Environmental Contamination and Toxicology, vol. 61, no. 3, pp. 368-375, 2011.

[15] I. Iida, T. Nomura, and S. Morlora, "Dyeing and dimensional stabilization of xylem utilizing the sap flow of freshly-felled trees," Kyoto Prefectural University (Agriculture Science), vol. 40, pp. 64-70, 1989.

[16] G. J. Zhao, "Stumpage dyeing techniques: China," 98102444.0, 1999.

[17] "Methods for analysis of waterborne wood preservatives," GB/T 23229-2009, Chinese Standard Press, Beijing, China, 2009.

[18] J. Zhang and P. Kamdem, "FTIR characterization of copper ethanolamine-wood interaction for wood preservation," Holzforschung, vol. 54, no. 2, pp. 119-122, 2000.

[19] X. Jiang and J. N. R. Ruddick, "Leaching resistance of copper amine-treated Scots pine," Forest Products Journal, vol. 54, no. 12, pp. 213-216, 2004.

[20] N. Druz, I. Andersone, and B. Andersons, "Interaction of copper-containing preservatives with wood. Part 1. Mechanism of the interaction of copper with cellulose," Holzforschung, vol. 55, no. 1, pp. 13-15, 2001.

[21] A. Pizzi, "Chromium interactions in CCA/CCB wood preservatives. Part I. Interactions with wood carbohydrates," Holzforschung, vol. 44, no. 5, pp. 373-380, 1990.

[22] A. Pizzi, "Chromium interactions in CCA/CCB wood preservatives. Part II. Interactions with lignin," Holzforschung, vol. 44, no. 6, pp. 419-424, 1990.

[23] J. N. R. Ruddick, C. S. Xie, and F. G. Herring, "Fixation of amine copper preservatives. Part 1. Reaction of vanillin, a lignin model compound with monoethanolamine copper sulphate solution," Holzforschung, vol. 55, no. 6, pp. 585-589, 2001.

[24] M. Scheikl and M. Dunky, "Measurement of dynamic and static contact angles on wood for the determination of its surface tension and the penetration of liquids into the wood surface," Holzforschung, vol. 52, no. 1, pp. 89-94, 1998.

[25] K. J. Duchow and R. A. Gerhardt, "Dielectric characterization of wood and wood infiltrated with ceramic precursors," Materials Science and Engineering C, vol. 4, no. 2, pp. 125-131, 1996.
[26] A. Mader, A. Schirò, M. Brischetto, and B. Pizzo, "Interactions and penetration of polymers and nanolatexes into wood: an overview," Progress in Organic Coatings, vol. 71, no. 2, pp. 123135,2011

[27] C. Lovisolo and A. Schubert, "Effects of water stress on vessel size and xylem hydraulic conductivity in Vitis vinifera L," Journal of Experimental Botany, vol. 49, no. 321, pp. 693-700, 1998.

[28] M. T. Tyree and F. W. Ewers, "The hydraulic architecture of trees and other woody plants," New Phytologist, vol. 119, no. 3, pp. 345-360, 1991.

[29] A. J. Stamm, "Movement of fluids in wood-part I: flow of fluids in wood," Wood Science and Technology, vol. 1, no. 2, pp. 122-141, 1967.

[30] A. Schubert, C. Lovisolo, and E. Peterlunger, "Shoot orientation affects vessel size, shoot hydraulic conductivity and shoot growth rate in Vitis vinifera L.," Plant, Cell and Environment, vol. 22, no. 2, pp. 197-204, 1999.

[31] Y. Wang and A. Schniewind, "Consolidation of deteriorated wood with soluble resins," Journal of the American Institute for Conservation, vol. 24, no. 2, pp. 77-91, 1985.

[32] A. K. Flynn, "A review of the permeability, fluid flow, and anatomy of spruce," Wood and Fibre Science, vol. 27, no. 3, pp. 278-284, 1995.

[33] H. Yamaguchi, "Low molecular weight silicic acid-norganic compound complex as wood preservative," Wood Science and Technology, vol. 36, no. 5, pp. 399-417, 2002.

[34] S. Saka, M. Sasaki, and M. Tanahashi, "Wood-inorganic composites prepared by sol-gel processing. 1. Wood-inorganic composites with porous structure," Mokuzai Gakkaishi, vol. 38, pp. 1043-1049, 1992.

[35] J. Przepiórski, A. W. Morawski, and A. Oya, "Method for preparation of copper-coated carbon material," Chemistry of Materials, vol. 15, no. 4, pp. 862-865, 2003.

[36] J. Haber, T. Machej, L. Ungier, and J. Ziółkowski, "ESCA studies of copper oxides and copper molybdates," Journal of Solid State Chemistry, vol. 25, no. 3, pp. 207-218, 1978. 

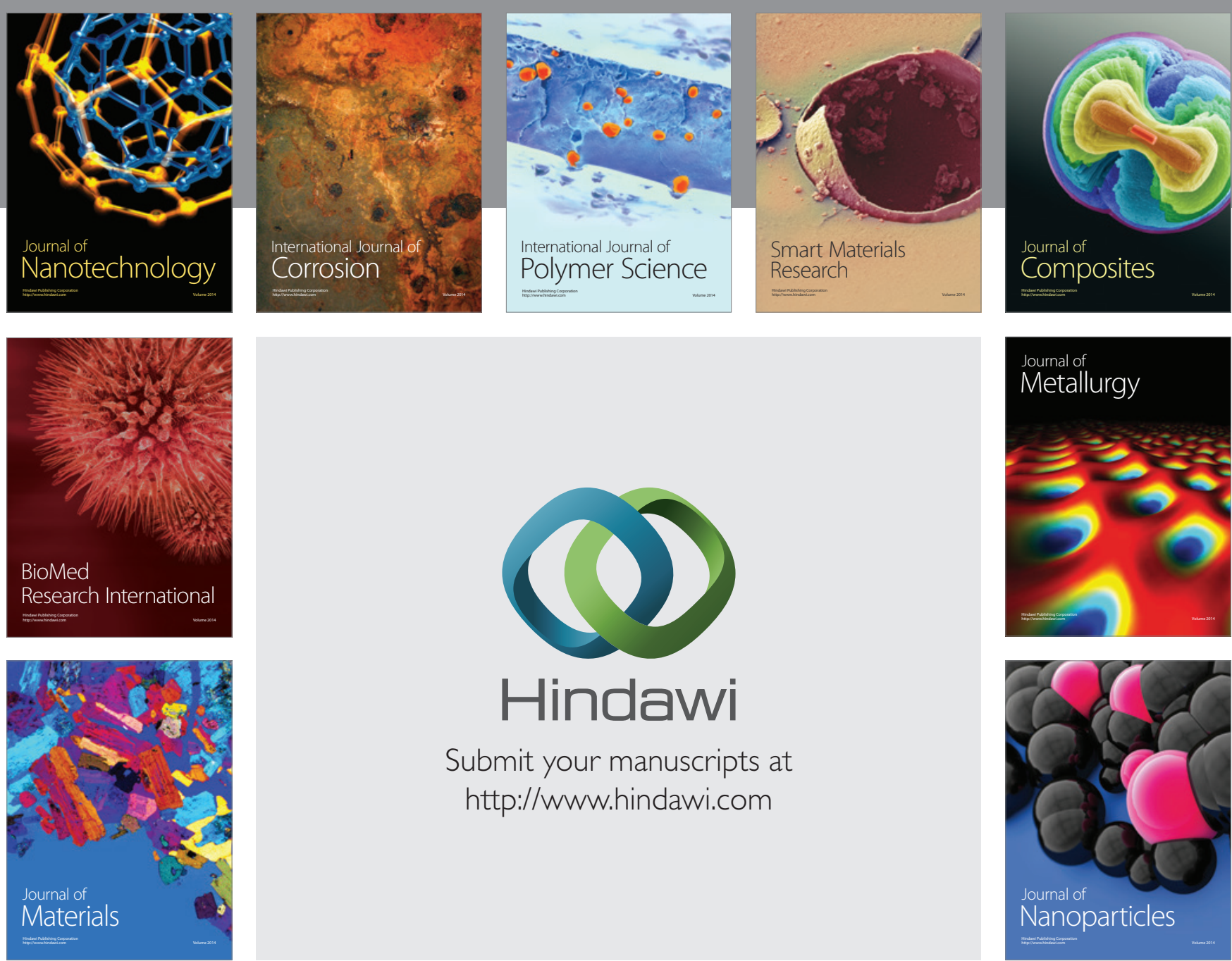

\section{Hindawi}

Submit your manuscripts at

http://www.hindawi.com

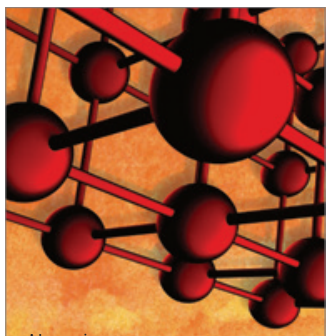

Materials Science and Engineering
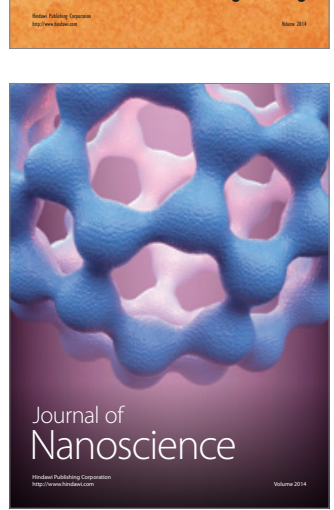
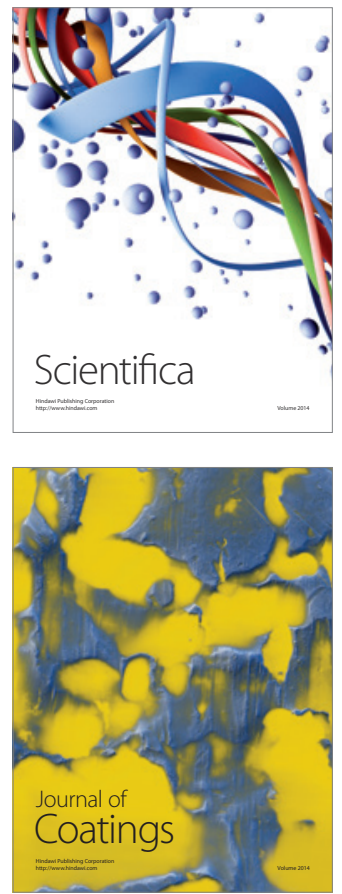
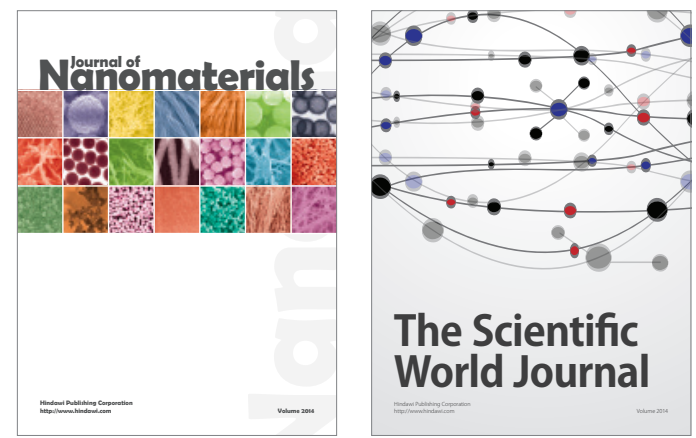

The Scientific World Journal
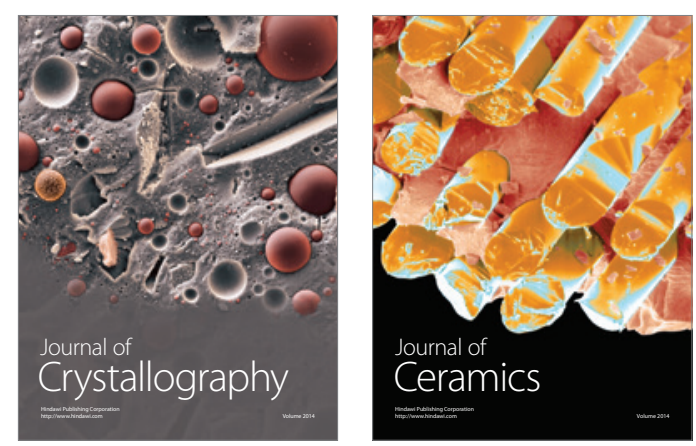
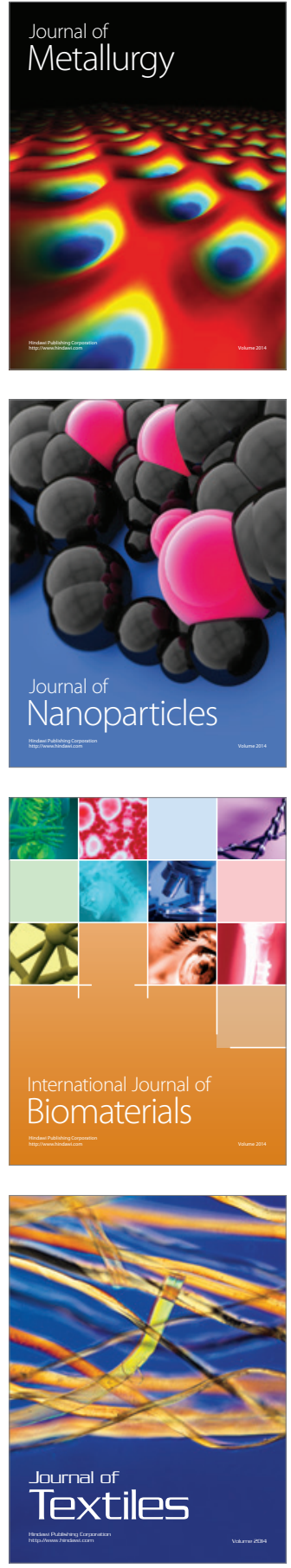